\title{
Uses of scanning electrochemical microscopy for the characterization of thin inhibitor films on reactive metals: The protection of copper surfaces by benzotriazole
}

\author{
Javier Izquierdo, Juan José Santana ${ }^{+}$, Sergio González, Ricardo M. Souto \\ Department of Physical Chemistry, University of La Laguna, E-38207 La Laguna, \\ Tenerife, Canary Islands, Spain \\ ${ }^{+}$On leave from the Department of Process Engineering, University of Las Palmas de \\ Gran Canaria, Campus Universitario de Tafira, E-35017 Las Palmas de Gran Canaria, \\ Canary Islands, Spain.
}

\begin{abstract}
$\underline{\text { Abstract }}$
Scanning electrochemical microscopy (SECM) was used to study the film formation of benzotriazole towards corrosion of copper. SECM was operated in the feedback mode by using ferrocene-methanol as redox mediator, and the sample was left unbiased at all times to freely attain its open circuit potential in the test environment. Following exposure to aggressive electrolytes the anticorrosion abilities of the layers were characterised by image analysis and by an electrochemical method derived from the experimental approach curves. Changes in the shape of the approach curves were clearly observed during the inhibitor film formation process. They showed the transition from an active conducting behaviour towards ferrocinium reoxidation typical of unprotected copper, to a surface exhibiting insulating characteristics when the metal was covered by a surface film containing the inhibitor. This supports that SECM is a practical technique in the investigation of corrosion inhibitor performance. However, a consistent tendency for the characterization of inhibitor film formation using SECM measurements in the positive feedback mode for the copper-benzotriazole system was only found when the experiments were conducted when the inhibitor molecule was not present in the test solution. That is, inhibitor molecules were found to interact not only with the copper surface during the monitoring process, but to interact with the SECM tip as well, this effect being significantly enhanced when chloride ions were present in the electrolyte. Finally, a procedure to image the chemical activity of copper surfaces partially covered with the inhibitor film with SECM is proposed.
\end{abstract}

Keywords: Corrosion inhibition; Copper; Benzotriazole; Scanning electrochemical microscopy. 


\section{Introduction}

Microelectrochemical techniques are becoming essential tools in the study of corrosion reactions, because they provide new in situ information on the processes involved, which are resolved simultaneously in space and time [1,2]. Furthermore, new information concerning earlier steps in the corrosion mechanisms can be gained through the design of experimental methods which are based in operation modes of some of these techniques [3-7]. Among the microelectrochemical techniques, the Scanning Electrochemical Microscope (SECM) [8] seems to be most specially suited for the investigation of such complex systems. It combines the local resolution characteristics of a scanning probe technique with the use of a microelectrode as sensing element, thus providing electrochemical resolution simultaneously. Thus, it is very appropriate to provide in situ topographic and electrochemical reactivity information about the surface evolution at the micrometer and submicrometer scale in aqueous solution. In addition, SECM has already been used in Corrosion Science for the detection of anodic and cathodic areas $[9,10]$, the dissolution of metals $[11]$, the investigation of the chemical stability of surface coatings [12,13], the degradation of organic films [14-22], the characterization of the metastable regime of pit nucleation [23], the detection of precursor sites for pitting inclusion dissolution [3,24,25], single pit generation [4-6,26$28]$, the monitoring of inclusion dissolution [29,30], and the imaging of surface changes during hydrogen permeation [31].

Another potential field of application for SECM in corrosion science is to study the film formation and destruction of corrosion inhibitor layers. Inhibition is one of the most important means for the protection of metals against corrosion. The effectiveness of organic inhibitors is related to the extent to which they adsorb and cover the metal oxide surface. The efficacy of inhibitors is normally investigated by gravimetric and electrochemical methods [32-39], including the electrochemical quartz crystal microbalance (EQCM) due to its ability to measure mass differences in the order of nanograms per surface area [40-45], and frequently assisted by surface analytical techniques such as X-ray photoelectron spectroscopy (XPS), Auger electron spectroscopy (AES), secondary ion mass spectrometry (SIMS), and laser micro mass analysis (LAMMA) [46-53]. Unfortunately, all these techniques exclusively provide global information as they lack enough spatial resolution, which is demanded to better understand the nature of the interactions and processes responsible for the inhibiting 
effect. Such knowledge is highly needed to elucidate the mechanisms involved, and it would facilitate inhibition to be optimized. This it the rational behind the introduction of scanning probe microscopies (SPM) to this work. Yet its application has been reduced to investigate how metal dissolution in acids is influenced by the inhibitor films already produced on the metal samples from imaging the surface morphological changes occurring in micrometer and nanometer scales [52-57].

The aim of this work is to explore the applicability of scanning electrochemical microscopy to the characterization of the formation and destruction of corrosion inhibiting films. The system copper/benzotriazole was chosen as an example of interface inhibition. Recently, Kontturi and coworkers have reported some investigations of this model metal-inhibitor system with the SECM operating in the feedback mode [58-60], and information regarding the kinetics of film formation and on the effects of oxygen contents in the environment and of copper polarization in the inhibitive effect of benzotriazole. In those investigations, Z-approach curves were employed exclusively, and ferrocene-methanol had to be added to the electrolyte to serve as redox mediator at the ultramicroelectrode tip. Despite these antecedents, no attempts have yet been made either to obtain SECM images of the inhibitor-covered copper samples, or to investigate the behaviour of the inhibitor on unpolarized copper samples.

Copper is a metal with a low redox potential in aqueous solutions [61], and it constitutes a representative example for the study of the electrochemical behaviour of passive materials. Copper is extensively used in various industrial applications due to its interesting properties, namely high electrical and thermal conductivities. Moreover, it exhibits a high corrosion resistance due to the formation at its surface of a uniform and adherent oxide film by the corrosion process itself. This passive film protects copper from the aggressive medium. The onset of passivity has been related to the formation of copper oxide layers with a duplex structure, consisting in general terms of an inner $\mathrm{Cu} / \mathrm{Cu}_{2} \mathrm{O}$ porous and an outer $\mathrm{CuO}$ hydrated layers [62-65]. However, in spite of this self-protecting property, copper is susceptible to corrosion by acids and strong alkaline solutions, especially in the presence of oxygen or oxidants. An oxide surface layer can only be formed in weak acid or alkaline solutions.

Heterocyclic organic compounds containing nitrogen, sulphur or oxygen atoms are often used to protect metals from corrosion due to the ability of the heterocyclic atoms to easily form bonds with transition metals such as copper. Thus, several 
inhibitors like azoles, triazoles, and sulfoxide derivatives have been known and successfully been applied for the protection of copper $[38,66]$, though so far, benzotriazole (BTAH) is probably the most efficient substance for the inhibition of copper corrosion in those environmental conditions, and it has become the most commonly used in practice.

The protecting effect of BTAH is based on the formation of a coordination polymer $[\mathrm{Cu}(\mathrm{I}) \mathrm{BTAH}]_{\mathrm{n}}$ on the surface of the metal featuring a $\mathrm{Cu}(\mathrm{I})$ center bridging between two BTAH molecules [67-69], and this layer inhibits the anodic reaction. Adsorption of BTAH is considered to be the initial step in the formation of the inhibiting layer, which is often represented as:

$$
\mathrm{Cu}(\mathrm{s})+\mathrm{BTAH}(\mathrm{aq})=\mathrm{Cu}: \mathrm{BTAH}(\mathrm{ads})
$$

The adsorbed layer containing this molecule is insoluble in water, and its thickness varies with both $\mathrm{pH}$ and the concentration of BTAH [70]. Subsequent thickening of the inhibiting layer is regarded to occur as $\mathrm{Cu}^{+}$species migrate through the $\mathrm{Cu}-\mathrm{BTAH}$ layer which are necessary to form the $\mathrm{Cu}(\mathrm{I})-\mathrm{BTAH}$ coordination polymer [71].

In this study of the application of scanning electrochemical microscopy to study the film formation and the stability of the protective film formed on copper by benzotriazole $(\mathrm{BTAH})$. The protection characteristics of the resulting layers against copper corrosion has been further investigated by considering the electrochemical behaviour of copper samples left unbiased at their open circuit potential in the aqueous environments containing either sulphate or chloride ions. SECM was operated in the feedback mode by using ferrocene-methanol as redox mediator, and the sample was left unbiased at all times to freely attain its open circuit potential in the test environment. Following exposure to aggressive electrolytes the anticorrosion protection abilities of the layers were characterised by image analysis and by an electrochemical method derived from the experimental approach curves. Additionally, the scanning vibrating electrode technique (SVET) [72,73] was employed in order to measure the local distribution of ionic current flows from both inhibitor-free and inhibitor-treated copper substrates, and complementary information to that obtained with the SECM could thus be obtained.

\section{Experimental}

\subsection{Materials}


The copper materials used in this study were available as copper sheets of thickness $1 \mathrm{~mm}$ and 99.99\% purity supplied by Goodfellow (Cambridge, UK). They were cut into square specimens of area $c a .1 \mathrm{~cm}^{2}$. The surface of the copper specimens was grounded mechanically with silicon carbide papers of 800 and 4000 grit and subsequently polished with aluminium micropolish $(0.3 \mathrm{~mm}$ particle size $)$. The resulting surfaces were degreased with acetone, abundantly rinsed with twice-distilled water and allowed to dry in air.

Benzotriazole (BTAH) (Avocado 15423) and ferrocene-methanol (Aldrich 335061) were used as received. Analytical grade potassium chloride $(\mathrm{KCl})$, sodium chloride $(\mathrm{NaCl})$ and sodium sulphate $\left(\mathrm{Na}_{2} \mathrm{SO}_{4}\right)$ were employed to prepare the base aqueous electrolytes. All aqueous solutions were prepared using ultra-pure water purified with a Milli-Q system from Millipore. All measurements were performed at ambient temperature in the naturally aerated solutions.

SECM measurements were performed in both BTAH-free and BTAH-containing solutions, in order to establish eventual interactions between the organic molecule and the sensing platinum microelectrode. $\mathrm{KCl}$ and $\mathrm{Na}_{2} \mathrm{SO}_{4}$ solutions were employed as base electrolytes. Two different procedures were employed for the monitoring of the formation of inhibitor films on the copper surfaces, namely: (1) measurements in inhibitor-containing solutions (in situ experiments), BTAH was added to either base electrolyte to attain a $0.33 \mathrm{mM}$ concentration; and (2) measurements in inhibitor-free solutions (ex situ experiments), copper surfaces were first pretreated by immersing the metal plates in $0.1 \mathrm{M}$ base electrolyte $+1 \mathrm{mM}$ BTAH solutions for different immersion times between 2 to $70 \mathrm{~min}$, subsequently removed and carefully rinsed with ultra-pure water, and finally immersed in $0.1 \mathrm{M} \mathrm{Na}_{2} \mathrm{SO}_{4}$ solution to perform the SECM measurements.

On the other hand, SVET experiments were performed following the ex situ experimental procedure described above, with the only difference that the actual SVET measurements were performed in $10 \mathrm{mM} \mathrm{NaCl}$ solution, which provided an aggressive environment with low-conductivity to monitor the onset of corrosion reactions in the samples.

\subsection{SECM instrumentation and experimental procedure}

SECM experiments were carried out by using a Sensolytics Scanning Electrochemical Microscope (Sensolytics, Bochum, Germany), controlled with a 
personal computer. All measurements were carried out in a three-electrode cell, located inside a Faraday cage. The electrodes were a $25 \mu \mathrm{m}$ platinum microelectrode as the probe, an $(\mathrm{Ag} / \mathrm{AgCl}, 3 \mathrm{M} \mathrm{KCl})$ reference electrode and a platinum wire as counter electrode, all set up in a cell made of polytetrafluoroethene. All potential values given below are referred to the $(\mathrm{Ag} / \mathrm{AgCl}, 3 \mathrm{M} \mathrm{KCl})$ reference electrode. Specimens were mounted horizontally facing upwards. In all experiments the copper sample was left unpolarized at its open-circuit corrosion potential. The micromanipulator stand of the SECM instrument was used to hold the microelectrode in place. Scans were conducted both vertically (Z-approach curves) and parallel (3D images) to the sample surface. The measurement of 3D images was performed with the microelectrode at a height of $15 \mu \mathrm{m}$ over the specimen surface.

Ferrocene-methanol was added to the test electrolyte solutions to act as electrochemical mediator at the tip. The oxidation of this redox mediator at the microelectrode was used to establish the height of the tip over the coated surface as described elsewhere [20], and then to image the surface in situ. During the measurements, the potential of the tip was held at $+0.50 \mathrm{~V}$ versus the $(\mathrm{Ag} / \mathrm{AgCl}, 3 \mathrm{M}$ $\mathrm{KCl}$ ) reference electrode to obtain a diffusion-limited tip current. In brief, the establishment of the operating tip distance over the sample was performed by slowly approaching the surface of an untreated copper sample with the tip and simultaneously recording the measured current at the microelectrode $v s$. $Z$ displacement. In this way, the true distance between the tip and the substrate could be determined for the height at which the microelectrode displacement was stopped when recording the approach curve. In our experiments the microelectrode was stopped when the measured current was equal to $75 \%$ of the steady-state value in the bulk of the electrolyte (in the forecoming, this position of the tip relative to the sample will be referred as the closest distance attained during the measurement of the approach curves in the "in situ tests"). After the corresponding Z-approach curve was obtained, it was modelled assuming that the reduction of the mediator at the surface was under kinetic control [74]. Subsequently, the tip was withdrawn to a distance of $250 \mu \mathrm{m}$ from the sample surface, and the cyclic voltammogram for the ferrocene-methanol/ferrocinium redox process was registered in order to monitor the surface state of the Pt microelectrode. After electrolyte exchange for the inhibitor-containing electrolyte to be placed in site, a new $Z$-approach curve could be measured by approaching the surface until the the closest distance attained during the measurement of the approach curve for the untreated copper 
sample. When 3D images of the chemical reactivity of the surface were to be recorded, the tip was always withdrawn to a distance of $15 \mu \mathrm{m}$ from the sample surface (i.e. constant height), and the positioning motors were employed to move the tip parallel to the surface at a scan rate of $30 \mu \mathrm{m} \mathrm{s}^{-1}$. All the 3D maps shown were recorded by shifting the microelectrode tip from left to right (i.e., they were built as a composition of $X$ displacement lines, which were stepwise shifted in the $Y$ direction).

\subsection{SVET instrumentation and experimental procedure}

The SVET instrumentation was manufactured by Applicable Electronics Inc. (MA, USA) and controlled by dedicated software. Further details can be found in the literature [75]. The technique is based upon the measurement of small potential variations in solution, associated to the ionic fluxes that arise from active sites at the surface due to metal corrosion, which originate a very minute electric field within an electrolyte medium [76]. The distribution of potentials and currents on the surface of the sample can be theoretically determined from the application of Laplace's equations and Ohm's law [72,77]. The microelectrode had a platinum tip with a diameter of $20 \mu \mathrm{m}$, the amplitude of the probe vibration was $20 \mu \mathrm{m}$, both parallel and normal to the surface, and its main position was located at a distance of $100 \mu \mathrm{m}$ from the sample. A calibration routine converts the measured potentials into current densities at the corroding surface [78]. The results are displayed as three-dimensional plots, with the current density (Zdirection) plotted as a function of the $(X, Y)$ position in the probe scan plane. A video microscope was used to aid microelectrode positioning and sample levelling using three thumbscrews arranged in a tripod configuration before the test electrolyte was introduced in the electrochemical cell. Furthermore, video microscope images were taken in situ both before and after recording each SVET map to assist in the observation of the most significant features occurring on the substrate surface with the elapse of time.

\section{Results and discussion}

\subsection{Use of ferrocene-methanol as redox mediator for SECM measurements}

SECM operation in the feedback mode required a suitable redox mediator to be added to the test electrolyte. Special caution had to be taken in relation to the choice of this electrochemical species in order to secure no spurious effects could be caused on the investigated copper and copper-BTAH samples due to either direct reaction or 
potential modification. The second effect is especially relevant for the system under investigation since reversible redox couples would modify the potential at the interface as predicted by the Nernst equation [79]. That is, the potential of the substrate could be determined by the redox mediator species if both species are simultaneously present in the environment. Both reported effects could be avoided by selecting ferrocenemethanol as redox mediator in our investigation. The redox potential for ferrocenemethanol oxidation to ferrocinium ion occurs at potential values very positive compared to the open circuit potential of the copper samples, thus maintaining ferrocene-methanol as the only stable species from this redox couple present in the electrolyte. The Nernst equation can only apply if the open circuit potential of the system under investigation would shift positively beyond the onset of ferrocene-methanol oxidation, in which case both ferrocene-methanol and the ferrocinium ion will be present in the electrolyte, and the potential would be determined by their concentration ratio.

\subsection{SECM Z-approach measurements}

Approach curves are obtained when the SECM-microelectrode is moved towards the surface in a controlled motion, with the result of variations in the signal measured at the tip as result of the near field effect originating in the proximity of the sample. The potential of the tip is set at $+0.50 \mathrm{~V}$ vs. $(\mathrm{Ag} / \mathrm{AgCl}, 3 \mathrm{M} \mathrm{KCl})$ [15] to attain the diffusioncontrolled oxidation of ferrocene-methanol to ferrocinium. Different behaviours are observed in conventional amperometric SECM depending on the conductive or insulating characteristics of the sample, which originate positive or negative feedback effects, respectively. These feedback effects could be employed to image the surface under investigation provided the sample is chemically-homogeneous and thus changes in the faradaic current measured at the tip could be directly correlated to the topography of the scanned surface.

\subsubsection{In situ experiments}

Fig. 1 shows selected Z-approach curves measured at different elapse times during the immersion of a copper sample in a sodium sulphate solution containing BTAH as corrosion inhibitor. All the plots were recorded by using the same maximum and minimum tip-substrate distances as chosen from the first approach curve determined as soon as the electrolyte was introduced in the electrochemical cell. From the inspection of this first amperometric curve, the characteristic positive-feedback 
behaviour of free copper can be clearly observed whereas the SECM tip approaches the surface, which is due to the regeneration of the ferrocene-methanol species on the conductive copper substrate. But with the elapse of time, the extent of this effect progressively diminishes, and it becomes hardly noticeable from the approach curve recorded at the end of the experiment (i.e., 17 hours) under the same scale. Despite the decrease of the positive feedback effect for longer exposures, no negative feedback effect was observed at any time in the system under these experimental conditions.

It has been shown that the formation and subsequent growth of the inhibitorcontaining film adsorbed on the surface of the copper sample progressively hinders the regeneration of ferrocene-methanol at the substrate, whereas diffusion of the redox mediator from the bulk electrolyte is made difficult when the tip-substrate distance is below one tip diameter because it occurs in the thin-electrolyte column existing below the tip. The net outcome is that smaller faradaic currents are measured at the tip for a given tip-substrate distance with the increase of immersion time, which is due to the adsorption of BTAH and the subsequent formation of the coordination polymer $\mathrm{Cu}(\mathrm{I}) \mathrm{BTAH}$ on the metal surface, thus originating a less-conductive substrate. An alternate procedure to follow the formation of the inhibitor film with time from the SECM measurements consists in plotting the values of the current measured at the distance of maximum approach employed in the work as a function of immersion time as depicted in Fig. 2. In this way the major decrease in current is found to occur during the first 50 minutes of immersion, and it progressive levels off for longer exposures (for the sake of clarity, only the values determined during the first $300 \mathrm{~min}$ are shown in the plot).

Similar experiments were conducted when the electrolyte contained chloride ions instead of sulphate ions, though at the same concentration, and the measured $z$ approach curves are depicted in Fig. 3. Though the positive feedback behaviour also occurred when the Z-approach curves were measured in the chloride-containing solution, significant changes in both the shape and the time evolution of these plots could be observed when they were compared with those determined in the sulphate base electrolyte (cf. Figs. 1 and 3). Firstly, all the plots show normalized currents significantly smaller than those found for the sulphate-containing electrolyte (i.e., the current values of these approach curves are comparable to those obtained for exposures in excess of $240 \mathrm{~min}$ in Fig. 1). Secondly, the approach curves in Fig. 3 exhibit very similar relationships between the current and the tip-substrate distance regardless the 
exposure time in the test environment, and even compared to the inhibitor-free condition. These two features may indicate that the adsorption of BTAH at the copper surface in the presence of free chloride ions in the electrolyte occurs significantly faster than in sodium sulphate solution, and that the initially formed inhibiting film exhibits enhanced insulating characteristics towards charge transfer. On the other hand, details on the kinetics of film formation from the SECM measurements could be attempted by plotting the values of the current measured at the distance of maximum approach as a function of immersion time, which is given in Fig. 4. The measurements seem to support that the protecting characteristics of the inhibitor film do not improve as compared to those formed during the first minute for exposures up to ca. $200 \mathrm{~min}$, but rather to be slightly more conductive (i.e. less protective) during this period of time, with a maximum around $100 \mathrm{~min}$. On the other hand, when the sample is exposed to the inhibitor-containing medium in excess of $200 \mathrm{~min}$, the inhibitor film progressively improves as time elapses.

The rather striking behaviour of the $\mathrm{Cu}-\mathrm{BTAH}$ system in a chloride-containing electrolyte just mentioned can be understood when the absolute current values measured at the SECM tip are considered instead. Tables 1 and 2 show the absolute current values measured at the distances of maximum and minimum approach from the $Z$-approach curves in either chloride or sulphate base electrolytes when they contain $0.33 \mathrm{mM}$ BTAH. The following observations can be made for a given microelectrode geometry and redox mediator concentration, namely: (1) the diffusion-limited current for ferrocene-methanol oxidation, $I_{l i m}$, is always smaller when benzotriazole is present in the test electrolyte; (2) the values of $I_{\text {lim }}$ consistently decrease as time elapses for the SECM tip immersed in an electrolyte containing the inhibitor molecule; (3) the magnitude of the positive feedback effect, as determined from the current values $\left(I_{\max }\right)$ measured at the tip when the minimum tip-substrate distance is attained, strongly depends on the composition of the base electrolyte, which is an evidence of the different chemical characteristics of the passive film developed on copper in contact from each electrolyte; and (4) the $I_{\max }$ values decrease as time elapses in the inhibitor-containing electrolyte, though they do not show the progressive dependency that can be found for $i_{\text {lim }}$ values instead. A satisfactory explanation for these facts must account for both the decrease in the diffusion-limited currents measured at the tip in the bulk electrolyte, and the smaller magnitude of the positive feedback effect during the in situ experiments when the base electrolyte contains chloride instead of sulphate. The steady decrease in 
the diffusion-limited currents with time measured when the tip is located far from the metal substrate is due to the interaction of the benzotriazole molecule with the platinum surface of the UME, which results in the partial blockage of the sensing tip, and hinders the application of SECM to characterize this reactive system. The decrease in the active area of the UME is clearly followed by measuring cyclic voltammograms for the ferrocene-methanol/ferrocinium system in benzotriazole-containing solutions just after recording the corresponding Z-approach curves. The CVs displayed in Figs. 5 and 6 were measured when the tip was located at a height of $250 \mu \mathrm{m}$ from the sample surface. It is directly observable that the magnitude of the diffusion limited current for ferrocene-methanol oxidation in the chloride-containing electrolyte continuously decreased with the elapse of time, an indication that the active area of the $\mathrm{Pt}$ microelectrode was effectively reduced due to the interaction of the organic inhibitor molecule with the metal, whereas such an effect was significantly smaller when the sulphate-based electrolyte was employed instead and required longer exposures to be significant (cf. the CV measured after $1020 \mathrm{~min}$ exposure in the electrolyte). Therefore, the surface of the sensing microelectrode is sensitive to modification by the benzotriazole molecule, and the reported changes in the faradaic currents measured at the Pt tip cannot be exclusively attributed to variations in the tip-substrate distance and the chemical state of the copper substrate, hindering the SECM to be employed to monitor the $\mathrm{Cu}$-BTAH films when the benzotriazole molecule is present in the electrolyte ("in situ tests"), and it would require to search for a different electrode material that would show no interaction with BTAH for the fabrication of the SECM tip. Since this feature is less notorious for the samples immersed in the $\mathrm{Na}_{2} \mathrm{SO}_{4}$ base electrolyte, it may have passed unnoticed in previous investigations from another laboratory [58-60]. Nevertheless, the interaction between platinum and benzotriazole cannot be neglected from the observations gathered during this work. On the other hand, it is impossible to establish from these measurements whether the formation of an inhibiting film on the copper surface from a chloride-containing electrolyte is faster than in sulphate, due to the reported uncertainties in the active area of the measuring tip, and it would be further addressed on the basis of the "ex situ experiments" described next.

\subsubsection{Ex situ experiments}

In the previous section, it has been demonstrated that the method to investigate the kinetics of inhibitor film formation based on the measurement of $Z$-approach curves 
with the SECM cannot be applied when the experiments are performed in situ, that is, in the inhibitor-containing electrolytes, because the adsorbing molecule will interact both with the metal surface to be protected and with the monitoring tip. To overcome this problem, "ex situ experiments" were next performed. The copper samples were treated by immersion in the inhibitor-containing electrolytes for selected times, subsequently removed and carefully rinsed with high-purity water, and the protection characteristics of the inhibitor films formed on the metal was investigated by SECM in an electrochemical cell containing a $0.1 \mathrm{M} \mathrm{Na}_{2} \mathrm{SO}_{4}$ solution using $1 \mathrm{mM}$ ferrocenemethanol as redox mediator.

Fig. 7 displays the Z-approach curves measured for copper samples pre-treated in $0.1 \mathrm{M} \mathrm{Na}_{2} \mathrm{SO}_{4}+1 \mathrm{mM}$ BTAH solution for different exposures as indicated. The positive feedback behaviour is clearly observed for those samples exposed to the inhibitor up to $70 \mathrm{~min}$, whereas the apparent negative feedback effect is found for significantly longer immersion times. The reason for this apparent negative feedback behaviour originates from the slower kinetics for ferrocinium reduction at the surface due to the progressive coverage of the sample by BTAH. A consistent decrease in the values of the normalized current measured at the tip for given tip-substrate distances is observed due to the progress of BTAH adsorption leading to either a greater surface coverage or the thickening of the inhibitor-containing passivating film as the duration of the treatment increases. The insulating characteristics of the protecting surface film improve as the film thickens, and the regeneration of ferrocene-methanol on the substrate is progressively hindered. Regeneration of the redox mediator is eventually completely impeded when a certain thickness of the surface film is attained, and then only a negative feedback effect can be observed.

The same ex situ experiment was conducted for copper samples protected with benzotriazole through their immersion in a chloride-containing electrolyte, and the measured Z-approach curves are plotted in Fig. 8. From the inspection of this figure, we can observe the same general trends reported above for the samples treated in sulphate environment, though it must be noted that the decrease in the currents for the positive feedback effect occurs faster in the case of those samples preconditioned in the chloride-containing electrolyte. This feature is more pronounced for the samples subjected to the shorter exposures, especially during the first 5 minutes of the treatment, an observation which is consistent with previous observations [80]. Therefore, the adsorption of BTAH on the copper surface is favoured by chloride ions, as well as the 
subsequent growth of the inhibiting passive film as compared to the behaviour of the system in a sulphate base electrolyte containing the same concentration of the inhibitor molecule. With the objective to facilitate the comparison of these results, a plot displaying the time evolution of the normalized current values measured when the tip was placed at the closest distance attained during the measurement of the approach curves depicted in Figs. 7 and 8 was prepared, and it is depicted in Fig. 9. Significantly smaller values are found for the dimensionless currents measured during the ex situ experiments. Therefore, it can be concluded that the progressive blockage of the active surface of the SECM tip by the benzotriazole molecules led to an overestimation of the normalized currents plotted in Figs. 2 and 4, and this variation was significant even during the period of time employed to record the approaching curve. Conversely, consistent time dependences are only observed for the inhibitive films formed ex situ, as observed from the comparison of Figs. 2, 4 and 9.

\section{2. $\underline{\text { SECM } X-Y \text { maps }}$}

The ex situ preconditioning procedure developed in Section 3.1.2 was next employed to prepare copper samples presenting various regions of different surface activity. The first set of experiments corresponds to that of bare copper and Cu-BTAH treated during different times in either sulphate- or chloride-base electrolytes. Inhibitormodified regions were obtained by dipping a freshly-polished copper sample in the BTAH-containing solution a half of its length for the chosen pre-treatment times, and subsequently rotated $90^{\circ}$ to dip a half of its width for another exposure. In this way, the resulting copper samples display four regions of different surface coverage by the inhibitor molecule, which correspond to bare copper, $\mathrm{Cu}$-BTAH treated for $5 \mathrm{~min}, \mathrm{Cu}-$ BTAH treated for $10 \mathrm{~min}$, and Cu-BTAH treated for $15 \mathrm{~min}$. A SEM micrograph taken from the centre of the sample where the four regions intersect is given in Fig. 10.

The samples were subsequently immersed in $0.1 \mathrm{M} \mathrm{Na}_{2} \mathrm{SO}_{4}+1 \mathrm{mM}$ ferrocenemethanol test solution and were left at their spontaneous open circuit potential in the electrolyte. The SECM images were recorded by rastering the tip at a constant height of $15 \mu \mathrm{m}$ selecting an area of the sample that would extend over portions of the 4 regions presenting different surface finishes, and the resulting SECM maps are depicted in Figs. 11 and 12. In both cases, the highest currents were observed above the untreated copper regions due to the regeneration of ferrocene-methanol over the free metal, whereas significantly smaller currents were measured above the BTAH-modified portions. 
Indeed, differences in surface reactivity among the regions covered by the inhibitor can be found in both SECM maps, which can be directly related to the duration of the pretreatment in the inhibitor-containing environment. Thus, the smallest currents were found above the $\mathrm{Cu}$-BTAH portion pre-treated for 15 minutes, though the effect is already clear when the pre-treatment only lasted 5 minutes, because the currents measured from that region are only slightly bigger than those from the portion pretreated for 15 minutes.

Though differences in surface activity could be readily observed among the $\mathrm{Cu}$ BTAH films formed in a given environment due to the formation of thicker films at longer exposures, the direct comparison of the SECM maps depicted in Figs. 11 and 12 do not allow possible changes in chemical reactivity due to the nature of the base electrolyte to be distinguished, i.e., to establish whether a specific effect of chloride ions towards the local chemistry of the resulting $\mathrm{Cu}-\mathrm{BTAH}$ films occurs. To this end, a second set of experiments was conducted as described next. They consisted in a pretreatment stage to form the $\mathrm{Cu}-\mathrm{BTAH}$ film by dipping a freshly-polished copper sample in the inhibitor-containing solution for 7 days. After the sample was removed and gently rinsed with ultra-pure water, the stability of the $\mathrm{Cu}$-BTAH films was investigated by exposing portions of the treated surface to an aggressive electrolyte solution such as 1 $\mathrm{M} \mathrm{NaCl}$ for various chosen exposure times. Four different conditions could be attained for each sample by following a procedure similar to that described in the previous paragraph. That is, about a half of the length of the sample was immersed for 16 hours, and subsequently rotated $90^{\circ}$ to dip a half of its width for an extra 8 hours exposure. In this way, the $\mathrm{Cu}-\mathrm{BTAH}$ samples would present four different zones corresponding to a non-exposed, and to exposures of 8,16 and 24 hours duration to the chloride environment, respectively. The samples were subsequently imaged in $0.1 \mathrm{M} \mathrm{Na}_{2} \mathrm{SO}_{4}+1$ $\mathrm{mM}$ ferrocene-methanol test solution by rastering the SECM tip at a constant height of $15 \mu \mathrm{m}$ selecting an area of the sample that would extend over portions of the 4 regions presenting different surface attacks.

Figs. 13 and 14 display the maps obtained for the $\mathrm{Cu}-\mathrm{BTAH}$ films formed in sulphate- and chloride-containing environments, respectively. The extent of chloride attack towards the $\mathrm{Cu}$-BTAH film can be seen as variations in the faradic current measured at the tip for ferrocene-methanol oxidation. The lowest currents are always observed for the zone that was not exposed to $1 \mathrm{M} \mathrm{NaCl}$ solution, and bigger currents are measured when the tip passes over those regions that have been exposed for longer 
periods of time. Yet, a major difference can be observed from the comparison of Figs. 13 and 14. The $\mathrm{Cu}-\mathrm{BTAH}$ film formed in the presence of sulphate ions is less resistant against the attack of the chloride ions in the inhibitor-free test environment, and deteriorates quite significantly during the duration of the experiments as demonstrated from the measurement of currents above the zone exposed during 24 hours that are effectively twice those measured above the unexposed zone (namely 1.0 and $0.5 \mathrm{nA}$, respectively, in Fig. 13). Conversely, the currents measured above the equivalent zones for the $\mathrm{Cu}$-inhibitor film formed in a chloride-containing medium only amount to 0.68 and $0.58 \mathrm{nA}$, respectively. This observation agrees with previous observations that a key factor in the formation of a Cu-BTAH film is the concentration of chloride ions in solution [81]. Furthermore, this experiment allows variations in the chemical stability of surface films formed in different conditions to be distinguished when imaged with the SECM during their exposure to an aggressive environment.

A final notice should be given in relation to the SECM images depicted in Figs. 11-14. They do not provide any topographical information as to consider that certain areas of the surface may be more prominent than others. The thicknesses of the $\mathrm{Cu}$ BTAH films formed in this work are below the detection limit of the technique as it corresponds to thin layers. Yet, differences in the electrochemical activity among different regions on the samples due to variations in the thickness and the surface coverage of the $\mathrm{Cu}$-inhibitor films are imaged by SECM. The occurrence of surface reactivity in these systems is further demonstrated when a $\mathrm{Cu}$-BTAH system exhibiting two regions of different inhibitor coverages which was imaged with the scanning vibrating electrode technique (SVET) in a solution free from ferrocene-methanol. The system was produced by dipping in $0.1 \mathrm{M} \mathrm{Na}_{2} \mathrm{SO}_{4}+1 \mathrm{mM} \mathrm{BTAH}$ a freshly-polished copper sample for about a half of its length from either side for the chosen pre-treatment times. Only a partial coverage of the metal surface was achieved when the sample was exposed for 3 seconds in the inhibitor-containing solution, whereas a rather continuous film occurred in the portion immersed during 60 minutes. The SVET images given in Fig. 15 show that corrosion of the metal occurs above the region that was exposed to BTAH during 3 seconds, with the development of a distribution of localized microanodes and microcathodes which are sources for the ionic flux of metal cations and hydroxyl anions, respectively. No evidence of electrochemical activity is observed at any times above the portion of the surface covered with the Cu-BTAH film in this mild corrosive medium. 


\section{Conclusions.}

We describe here the operations and basic requirements for scanning electrochemical microscopy to be successfully employed for the characterization of thin inhibitor films formed on reactive metals such as copper. The reported data show promising results based in the measurement of $Z$-approach curves and spatially-resolved 3D images of the electrochemical activity of substrates when SECM is operated in the feedback mode.

Though in situ SECM experiments can be performed for this system, that is, when the inhibitor molecule is present in the test electrolyte, and the results seem to be consistent with previous observations concerning a thicker and more insulating barrier film of $\mathrm{Cu}-\mathrm{BTAH}$ as time elapses, and that such a film is formed at a faster rate in a chloride-containing environment, the observations must be considered with great caution. It has been demonstrated that surface active molecules such as benzotriazole not only interact with the metal surface to protect (copper in this case), but they exhibit chemical activity towards the SECM tip. In this way, the currents measured at the SECM tip during near-field operation do not exclusively arise from variations in the activity of the investigated surface, but from surface blockage of the tip as well.

The design of "ex situ tests" is thus recommended, as they can be used for SECM to be employed as a very valuable tool to gain information regarding the kinetics of inhibitor film formation and to image changes both in the surface activity of metalinhibitor films arising from different pre-treatment conditions and in the extent of corrosion attack.

\section{Acknowledgement:}

We are grateful to the Ministerio de Ciencia e Innovación (Madrid, Spain) within the framework of Projects CTQ2005-06446/BQU and CTQ2009-12459/PPQ, under which the present work was carried out. The award by Ministerio de Educación y Ciencia of a collaborative research fellowship to J.I. is acknowledged, as well as a grant awarded to J.J.S. by the Gobierno de Canarias (Spain) to conduct a research stay at the University of La Laguna. 


\section{References:}

1. P. Marcus, F. Mansfeld F (Eds): Analytical methods in corrosion science and Engineering. CRC Press, Boca Raton (FL), 2006.

2. R. Oltra, V. Maurice, R. Akid, P. Marcus (Eds): Local probe techniques for corrosion research. Woodhead Publishing, Cambridge (England), 2007.

3. S.B. Basame, H.S. White, J. Phys. Chem. 99 (1995) 16430.

4. J.W. Still, D.O. Wipf, J. Electrochem. Soc. 144 (1997) 2657.

5. K. Fushimi, K. Azumi, M. Seo, J. Electrochem. Soc. 147 (2000) 552.

6. C. Gabrielli, S. Joiret, M. Keddam, H. Perrot, P. Rousseau, V. Vivier, J. Electrochem. Soc. 153 (2006) B68.

7. K. Eckhard, T. Erichsen, M. Stratmann, W. Schuhmann, Chem. Eur. J. 14 (2008) 3968.

8. A.J. Bard, M.V. Mirkin (Eds.): Scanning electrochemical microscopy. Marcel Dekker, New York, 2001.

9. A.C. Bastos, A.M. Simões, S. González, Y. González-García, R.M. Souto, Electrochem. Commun. 6 (2004) 1212.

10. A.M. Simões, A.C. Bastos, M.G. Ferreira, Y. González-García, S. González, R.M. Souto, Corros. Sci. 49 (2007) 726.

11. K. Fushimi, M. Seo, Electrochim. Acta 47 (2001) 121

12. S. Hocevar, S. Daniele, C. Bragato, B. Ogorevic, Electrochim. Acta 53 (2007) 555.

13. D. Battistel, S. Daniele, R. Gerbasi, M.A. Baldo, Thin Solid Films 518 (2010) 2195.

14. R.M. Souto, Y. González-García, S. González, G.T. Burstein, Corros. Sci. 46 (2004) 2621.

15. A.C. Bastos, A.M. Simões, S. González, Y. González-García, R.M. Souto, Prog. Org. Coat. 53 (2005) 177.

16. R.M. Souto, Y. González-García, S. González, Corros. Sci. 47 (2005) 3312.

17. A.M. Simões, D. Battocchi, D.E. Tallman, G.P. Bierwagen, Corros. Sci. 49 (2007) 3838.

18. R.M. Souto, Y. González-García, S. González, Corros. Sci. 50 (2008) 1637.

19. R.M. Souto, Y. González-García, S. González, Prog. Org. Coat. 65 (2009) 435.

20. R.M. Souto, Y. González-García, S. González, G.T. Burstein, Electroanalysis 21 (2009) 2569.

21. R.M. Souto, L. Fernández-Mérida, S. González, Electroanalysis 21 (2009) 2640. 
22. R.M. Souto, Y. González-García, J. Izquierdo, S. González, Corros. Sci. 52 (2010) 748.

23. Y. González-García, G.T. Burstein, S. González, R.M. Souto, Electrochem. Commun. 6 (2004) 637.

24. N. Casillas, S. Charlebois, W.H. Smyrl, H.S. White, J. Electrochem. Soc. 141 (1994) 636.

25. Y.Y. Zhu, D.E. Williams, J. Electrochem. Soc. 144 (1997) L43.

26. F. Falkenberg, K. Fushimi, M. Seo, Corros. Sci. 45 (2003) 2657.

27. C. Gabrielli, S. Joiret, M. Keddam, H. Perrot, N. Portail, P. Rousseau, V. Vivier, Electrochim. Acta 52 (2007) 7706.

28. C. Gabrielli, S. Joiret, M. Keddam, N. Portail, P. Rousseau, V. Vivier, Electrochim. Acta 53 (2008) 7539.

29. C.H. Paik, H.S. White, R.C. Alkire, J. Electrochem. Soc. 147 (2000) 4120.

30. C.H. Paik, R.C. Alkire, J. Electrochem. Soc. 148 (2001) B276.

31. S. Modiano, J.A.V. Carreno, C.S. Fugivara, R.M. Torresi, V. Vivier, A.V. Benedetti, O. R. Mattos, Electrochim. Acta 53 (2008) 3670.

32. J.B. Cotton, I.R. Scholes, Brit. Corros. J. 2 (1967) 1.

33. G.W. Poling, Corros. Sci. 10 (1970) 359.

34. M.M. Laz, R.M. Souto, S. González, R.C. Salvarezza, A.J. Arvia, J. Appl. Electrochem. 22 (1992) 1129.

35. S. González, M.M. Laz, R.M. Souto, R.C. Salvarezza, A.J. Arvia, Corrosion 49 (1993) 450.

36. F. Zucchi, M. Fonsati, G. Trabanelli, in: Giornate Nationali Sulla Corrosione e Protezione, 3rd edition. AIM, Milano, 1996, p. 115.

37. K. Rahmouni, N. Hajjaji, M. Keddam, A. Shriri, H. Takenouti, Electrochim. Acta 52 (2007) 7519.

38. M.M. Antonijević, S. Milić, M.B. Petrović, Corros. Sci. 51 (2009) 1228.

39. J. Aljourani, K. Raeissi, M.A. Golozar, Corros. Sci. 51 (2009) 1836.

40. Y. Yamamoto, H. Nishihara, K. Aramaki, J. Electrochem. Soc. 140 (1993) 436.

41. N. Ohno, J. Uehara, K. Aramaki, J. Electrochem. Soc. 140 (1993) 2512.

42. D. Jope, J. Sell, H.W. Pickering, K.G. Weil, J. Electrochem. Soc. 142 (1995) 2170.

43. A. Shaban, E. Kálmán, J. Telegdi, Gy. Dóra, J. Appl. Phys. A 66, (1998) 545.

44. E. Szöcs, Gy. Vastag, A. Shaban, G. Konczos, E. Kálmán, J. Appl. Electrochem. 29 (1999) 1339. 
45. Gy. Vastag, E. Szöcs, A. Shaban, I. Bertóti, K. Popov-Pergal, E. Kálmán, Solid State Ionics 141-142 (2001) 87.

46. R. Holm, D. Holtkamp, R. Kleinstück, H.-J. Rother, S. Storp, Fresenius Z. Anal. Chem. 333 (1989) 546.

47. D.M. Briggs, M.P. Seah (Eds.): Practical Surface Analysis. Vol. 1: AES and XPS. Wiley, New York, 1990.

48. R.V. Varma, J.R. Selman (Eds.): Techniques for Characterization of Electrodes and Electrochemical Processes. Wiley, New York, 1991.

49. R.M. Souto, V. Fox, M. Pérez, M.M. Laz, S. González, Mater. Sci. Forum 192-194 (1995) 385.

50. R.M. Souto, V. Fox, M.M. Laz, M. Pérez, S. González, J. Electroanal. Chem. 411 (1996) 161.

51. T. Kosec, D.K. Merl, I. Milošev, Corros. Sci. 50 (2008) 1987.

52. B.J. Cruickshank, A.A. Gewirth, R.M. Rynders, R. Alkire, J. Electrochem. Soc. 139 (1992) 2829.

53. M.R. Vogt, W. Polewska, O.M. Magnussen, R.J. Behm, J. Electrochem. Soc. 144 (1997) L113.

54. M.R. Vogt, A. Lachenwitzer, O.M. Magnussen, R.J. Behm, Surf. Sci. 399 (1998) 49.

55. W. Polewska, M.R. Vogt, O.M. Magnussen, R.J. Behm, J. Phys. Chem. B 103 (1999) 10440.

56. E. Szöcs, I. Bakó, T. Kosztolányi, I. Bertóti, E. Kálmán. Electrochim. Acta 49 (2004) 1371

57. A. Paszternák, S. Stichleutner, I. Felhösi, Z. Keresztes, F. Nagy, E. Kuzmann, A. Vértes, Z. Homonnay, G. Petö, E. Kálmán, Electrochim. Acta 53 (2007) 337.

58. K. Mansikkamäki, P. Ahonen, G. Fabricius, L. Murtomäki, K. Kontturi, J. Electrochem. Soc. 152 (2005) B12.

59. K. Mansikkamäki, C. Johans, K. Kontturi, J. Electrochem. Soc. 153 (2006) B311.

60. K. Mansikkamäki, C. Johans, K. Kontturi, J. Electrochem. Soc. 153 (2006) B22.

61. M. Pourbaix, Atlas of Electrochemical Equilibria in Aqueous Solutions. NACE, Houston, 1974.

62. H.D. Speckmann, M.M. Lohrengel, J.W. Schultze, H.H. Strehblow, Ber. Bunsenges. Physik. Chem. 89 (1985) 392.

63. M. Pérez Sánchez, M. Barrera, S. González, R.M. Souto, R.C. Salvarezza, A.J. Arvia, Electrochim. Acta 35 (1990) 1337. 
64. R.M. Souto, M. Pérez Sánchez, M. Barrera, S. González, R.C. Salvarezza, A.J. Arvia, Electrochim. Acta 37 (1992) 1437.

65. S. González, M. Pérez, M. Barrera, A.R. González Elipe, R.M. Souto, J. Phys. Chem. B 102 (1998) 5483.

66. Y.I. Kuznetzov, in Organic Inhibitors of Corrosion of Metals, A.D. Mercer, J.G.N. Thomas (Eds.). Plenum Press, New York, 1996, p. 101.

67. M.M. Antonijević, S.M. Milić, S.M. Ŝerbula, G.D. Bogdanović, Electrochim. Acta 50 (2005) 3693.

68. Y.N. Prasad, S. Ramanathan, Electrochim. Acta 52 (2007) 6353.

69. J.H. Chen, Z.C. Lin, S. Chen, L.H. Nie, S.Z. Yao, Electrochim. Acta 43 (1998) 265.

70. J.-O. Nilsson, C. Törnkvist, B. Liedberg, Appl. Surf. Sci. 37 (1989) 306.

71. K.L. Stewart, J. Zhang, S. Li, P.W. Carter, A.A. Gewirth, J. Electrochem. Soc. 154 (2007) D57.

72. H.S. Isaacs, J. Electrochem. Soc. 138 (1991) 723.

73. R.S. Lillard, in: Analytical methods in corrosion science and Engineering, P. Marcus, F. Mansfeld F (Eds). CRC Press, Boca Raton (FL), 2006, Ch. 15.

74. A.J. Bard and M.V. Mirkin (Eds.), Scanning Electrochemical Microscopy, Marcel Dekker, New York, 2001, p. 243.

75. A.C. Bastos, M.G.S. Ferreira, A.M. Simões, Prog. Org.Coat. 52 (2005) 339.

76. J. He, Applications of the scanning vibrating electrode technique to the study of corrosion protection by conductive polymers, Ph.D. Thesis, North Dakota State University, 2002.

77. G. Baril, C. Blanc, M. Keddam, N. Pébère, J. Electrochem. Soc. 150 (2003) B488.

78. C. Sheffey, in: Ionic Currents in Development, A. R. Liss (Ed.). A.R. Liss Inc., New York, 1986, p. xxv.

79. P. Sun, F.O. Laforge, M.V. Mirkin, Phys. Chem. Chem. Phys. 9 (2007) 802.

80. K. Yliniemi, Different Approaches for Surface Modifications: Formation of Inhibitive Film on Copper Surfaces and Surfaces Functionalised with Ag Nanoparticles, TKK Dissertations 105, Espoo, 2008.

81. T. Hashemi, C.A. Hogarth, Electrochim. Acta 33 (1988) 1123. 


\section{Table 1}

Time evolution of the absolute current values measured when the SECM tip was placed at the point of closest approach to the surface $\left(I_{\max }\right)$ and in the bulk electrolyte $\left(I_{\text {lim }}\right)$ during "in situ tests" carried out in a $0.067 \mathrm{M} \mathrm{Na}_{2} \mathrm{SO}_{4}+0.33 \mathrm{mM} \mathrm{BTAH}+0.67 \mathrm{mM}$ ferrocene-methanol solution with a $25 \mu \mathrm{m}$ Pt electrode.

\begin{tabular}{|c|c|c|}
\hline Time $/ \mathrm{min}$ & $I_{\text {max }} / \mathrm{nA}$ & $I_{\text {lim }} / \mathrm{nA}$ \\
\hline 0 & 6.53 & 2.16 \\
\hline 3 & 6.62 & 2.37 \\
\hline 6 & 6.46 & 2.40 \\
\hline 10 & 6.25 & 2.39 \\
\hline 30 & 5.12 & 2.23 \\
\hline 65 & 4.20 & 2.21 \\
\hline 90 & 3.93 & 2.18 \\
\hline 120 & 3.60 & 2.18 \\
\hline 150 & 3.41 & 2.20 \\
\hline 180 & 3.19 & 2.21 \\
\hline 210 & 3.08 & 2.22 \\
\hline 240 & 2.99 & 2.24 \\
\hline 270 & 2.92 & 2.26 \\
\hline 10200 & 1.77 & 1.61 \\
\hline
\end{tabular}




\section{Table 2}

Time evolution of the absolute current values measured when the SECM tip was placed at the point of closest approach to the surface $\left(I_{\max }\right)$ and in the bulk electrolyte $\left(I_{\text {lim }}\right)$ during "in situ tests" carried out in a $0.067 \mathrm{M} \mathrm{KCl}+0.33 \mathrm{mM}$ BTAH $+0.67 \mathrm{mM}$ ferrocene-methanol solution with a $25 \mu \mathrm{m}$ Pt electrode.

\begin{tabular}{|c|c|c|}
\hline Time/min & $I_{\max } / \mathrm{nA}$ & $I_{\text {lim }} / \mathrm{nA}$ \\
\hline 0 & 3.15 & 2.15 \\
\hline 3 & 3.14 & 2.40 \\
\hline 6 & 3.08 & 2.37 \\
\hline 10 & 3.11 & 2.37 \\
\hline 20 & 3.14 & 2.40 \\
\hline 30 & 3.06 & 2.31 \\
\hline 45 & 3.05 & 2.30 \\
\hline 60 & 3.07 & 2.32 \\
\hline 90 & 3.06 & 2.31 \\
\hline 120 & 3.03 & 2.30 \\
\hline 150 & 2.97 & 2.26 \\
\hline 180 & 2.89 & 2.22 \\
\hline 210 & 2.81 & 2.18 \\
\hline 240 & 2.73 & 2.13 \\
\hline 265 & 2.50 & 1.99 \\
\hline 290 & 2.35 & 1.89 \\
\hline
\end{tabular}




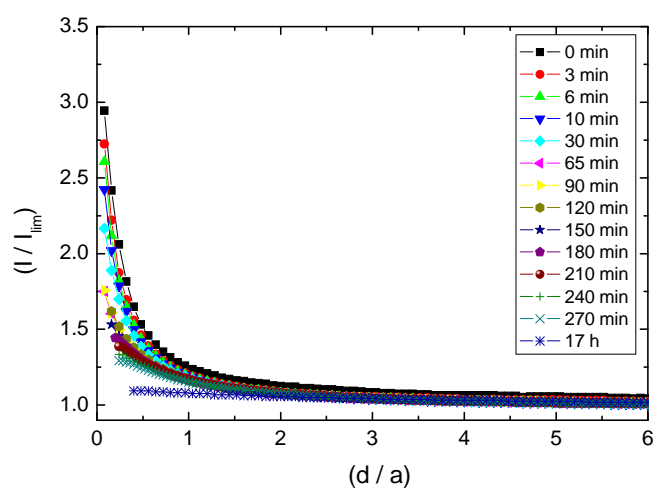

Figure 1: SECM normalized z-approach curves towards a copper surface measured in BTAH-containing electrolyte (i.e. "in situ test"). Experiments were carried out in a $0.067 \mathrm{M} \mathrm{Na}_{2} \mathrm{SO}_{4}+0.33 \mathrm{mM} \mathrm{BTAH}+0.67 \mathrm{mM}$ ferrocene methanol solution with a 25 $\mu \mathrm{m}$ Pt electrode. Tip potential: $+0.50 \mathrm{~V}$ vs. $(\mathrm{Ag} / \mathrm{AgCl}, 3 \mathrm{M} \mathrm{KCl})$. The sample was left at its spontaneous open circuit potential in the electrolyte and the curves were measured for the immersion times indicated in the figure. $I / I_{\text {lim }}$ is the dimensionless tip current, and $d / a$ is the dimensionless distance between the sample and the tip.

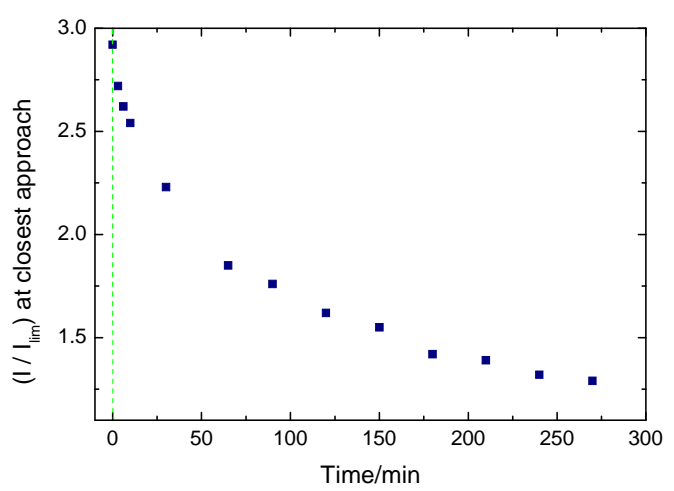

Figure 2: Time evolution of the normalized current values measured when the tip was placed at the closest distance attained during the measurement of the approach curves in the "in situ tests". Experiments were carried out in a $0.067 \mathrm{M} \mathrm{Na}_{2} \mathrm{SO}_{4}+0.33 \mathrm{mM}$ $\mathrm{BTAH}+0.67 \mathrm{mM}$ ferrocene methanol solution with a $25 \mu \mathrm{m}$ Pt electrode. Tip potential: $+0.50 \mathrm{~V}$ vs. $(\mathrm{Ag} / \mathrm{AgCl}, 3 \mathrm{M} \mathrm{KCl})$. 


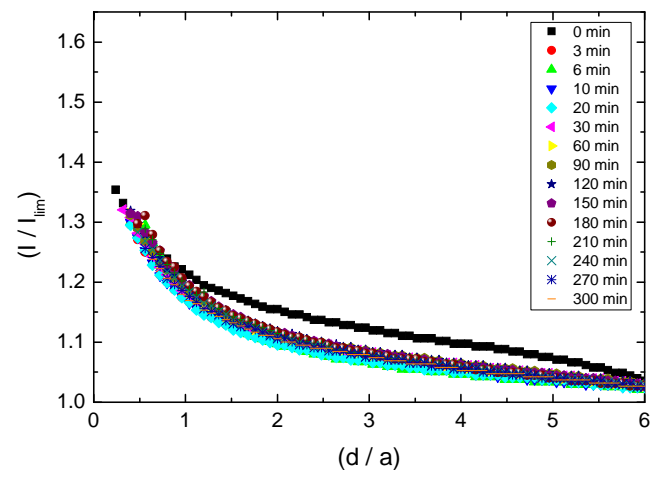

Figure 3: SECM normalized z-approach curves towards a copper surface measured in BTAH-containing electrolyte (i.e. "in situ test"). Experiments were carried out in a $0.067 \mathrm{M} \mathrm{KCl}+0.33 \mathrm{mM} \mathrm{BTAH}+0.67 \mathrm{mM}$ ferrocene methanol solution with a $25 \mu \mathrm{m}$ Pt electrode. Tip potential: $+0.50 \mathrm{~V}$ vs. $(\mathrm{Ag} / \mathrm{AgCl}, 3 \mathrm{M} \mathrm{KCl})$. The sample was left at its spontaneous open circuit potential in the electrolyte and the curves were measured for the immersion times indicated in the figure.

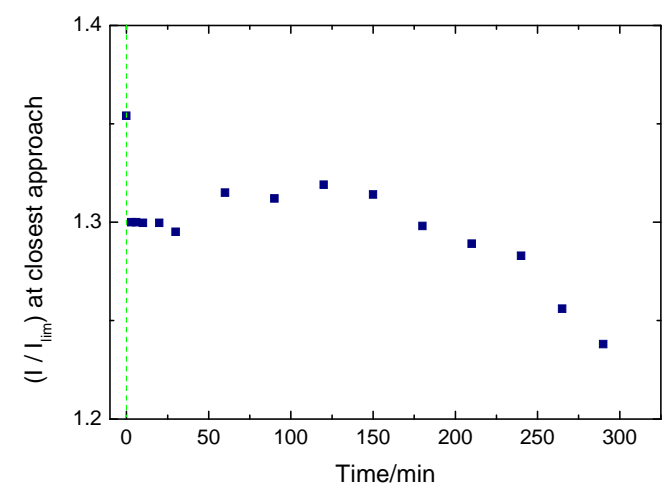

Figure 4: Time evolution of the normalized current values measured when the tip was placed at the closest distance attained during the measurement of the approach curves in the "in situ tests". Experiments were carried out in a $0.067 \mathrm{M} \mathrm{KCl}+0.33 \mathrm{mM} \mathrm{BTAH}+$ $0.67 \mathrm{mM}$ ferrocene methanol solution with a $25 \mu \mathrm{m}$ Pt electrode. Tip potential: $+0.50 \mathrm{~V}$ vs. $(\mathrm{Ag} / \mathrm{AgCl}, 3 \mathrm{M} \mathrm{KCl})$. 


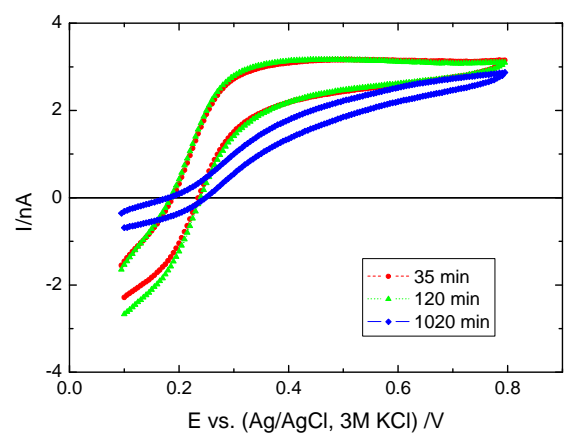

Figure 5: Cyclic voltammograms measured at the SECM-tip in a $0.067 \mathrm{M} \mathrm{Na}_{2} \mathrm{SO}_{4}$ $+0.33 \mathrm{mM} \mathrm{BTAH}+0.67 \mathrm{mM}$ ferrocene methanol solution with a $25 \mu \mathrm{m}$ Pt electrode. Tip-substrate distance: $250 \mu \mathrm{m}$. Scan rate: $v=0.10 \mathrm{~V} \mathrm{~s}^{-1}$. The voltammograms were measured just before recording the z-approach curves shown in Fig. 1. The curves correspond to the immersion times indicated in the figure.

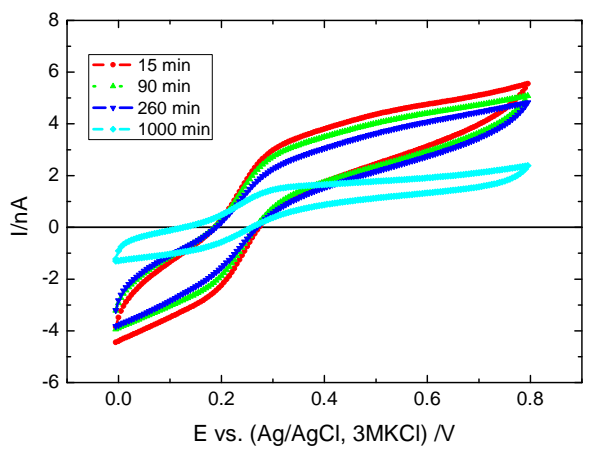

Figure 6: Cyclic voltammograms measured at the SECM-tip in a $0.067 \mathrm{M} \mathrm{KCl}+$ $0.33 \mathrm{mM}$ BTAH $+0.67 \mathrm{mM}$ ferrocene methanol solution with a $25 \mu \mathrm{m}$ Pt electrode. Tip-substrate distance: $250 \mu \mathrm{m}$. Scan rate: $v=0.10 \mathrm{~V} \mathrm{~s}^{-1}$. The voltammograms were measured just before recording the z-approach curves shown in Fig. 3. The curves correspond to the immersion times indicated in the figure.

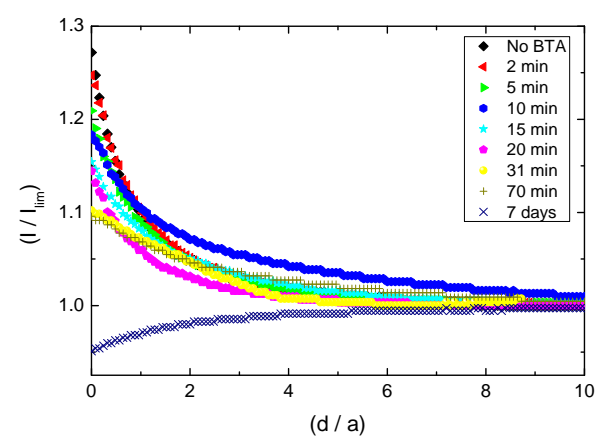

Figure 7: SECM normalized z-approach curves towards a copper surface measured in an inhibitor-free electrolyte (i.e. "ex situ test"). The pre-treatment of the copper samples was conducted in $0.1 \mathrm{M} \mathrm{Na}_{2} \mathrm{SO}_{4}+1 \mathrm{mM} \mathrm{BTAH}$ solution for different immersion times as indicated in the figure. SECM experiments were carried out in a $0.1 \mathrm{M} \mathrm{Na}_{2} \mathrm{SO}_{4}+1$ $\mathrm{mM}$ ferrocene methanol solution with a $25 \mu \mathrm{m}$ Pt electrode. Tip potential: $+0.50 \mathrm{~V}$ vs. $(\mathrm{Ag} / \mathrm{AgCl}, 3 \mathrm{M} \mathrm{KCl})$. The sample was left at its spontaneous open circuit potential in the electrolyte. 


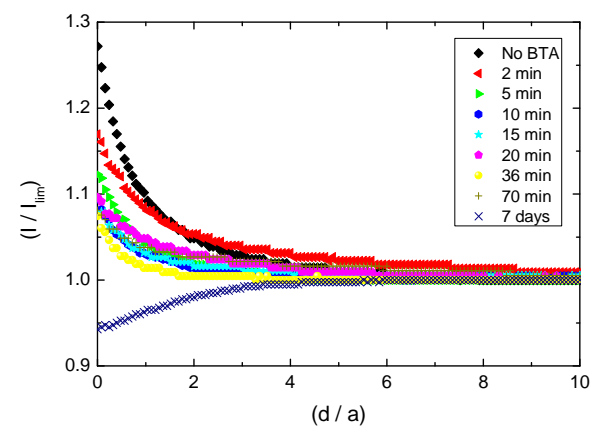

Figure 8: SECM normalized z-approach curves towards a copper surface measured in an inhibitor-free electrolyte (i.e. "ex situ test"). The pre-treatment of the copper samples was conducted in $0.1 \mathrm{M} \mathrm{KCl}+1 \mathrm{mM}$ BTAH solution for different immersion times as indicated in the figure. SECM experiments were carried out in a $0.1 \mathrm{M} \mathrm{Na}_{2} \mathrm{SO}_{4}+1 \mathrm{mM}$ ferrocene methanol solution with a $25 \mu \mathrm{m}$ Pt electrode. Tip potential: $+0.50 \mathrm{~V}$ vs. $(\mathrm{Ag} / \mathrm{AgCl}, 3 \mathrm{M} \mathrm{KCl})$. The sample was left at its spontaneous open circuit potential in the electrolyte.

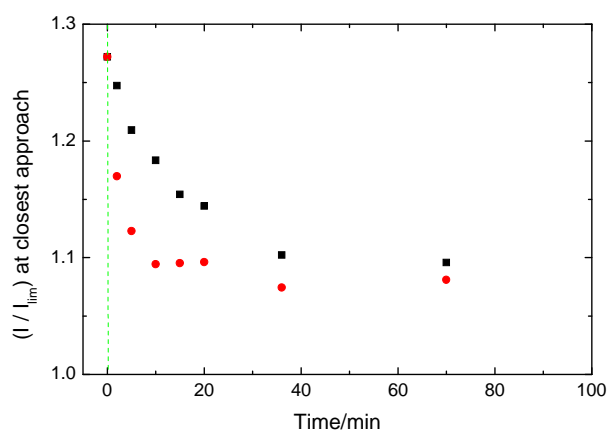

Figure 9: Time evolution of the normalized current values measured when the tip was placed at the closest distance attained during the measurement of the approach curves depicted in Figs. 7 and 8 corresponding to "ex situ tests". The inhibitor molecule was contained in either $(\bullet) 0.1 \mathrm{M} \mathrm{KCl}$ or $(\boldsymbol{\square}) 0.1 \mathrm{M} \mathrm{Na}_{2} \mathrm{SO}_{4}$ aqueous solution.

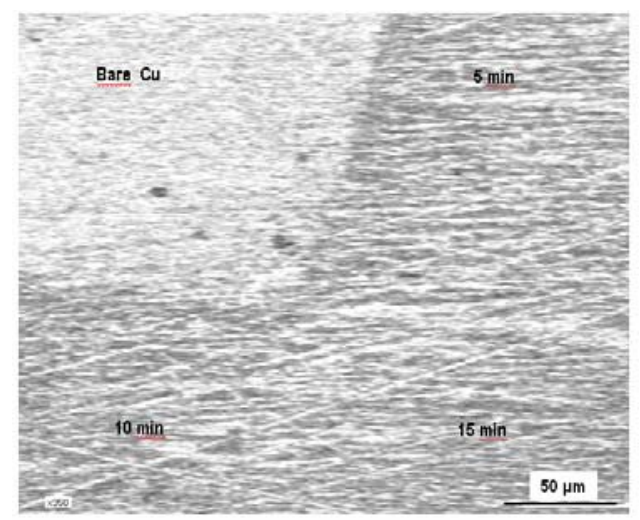

Figure 10: Scanning electron micrograph of a untreated $\mathrm{Cu}-\mathrm{Cu}-\mathrm{BTAH}$ (5 min pretreatment) - Cu-BTAH (10 min pre-treatment) - Cu-BTAH (15 min pre-treatment) system. The pre-treatment of the copper samples was conducted in $0.1 \mathrm{M} \mathrm{KCl}+1 \mathrm{mM}$ BTAH solution. 


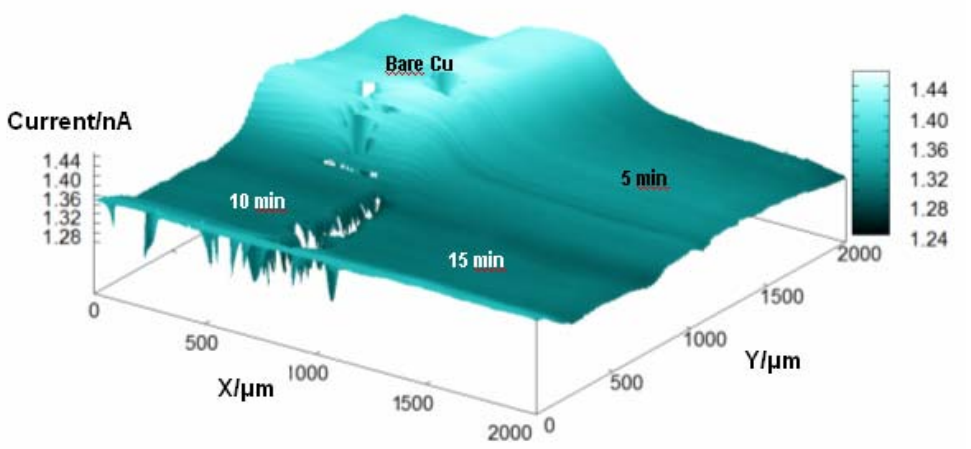

Figure 11: Image generated by SECM of a untreated $\mathrm{Cu}-\mathrm{Cu}-\mathrm{BTAH}$ (5 min pretreatment) - Cu-BTAH (10 min pre-treatment) - Cu-BTAH (15 min pre-treatment) system immersed in $0.1 \mathrm{M} \mathrm{Na}_{2} \mathrm{SO}_{4}+1 \mathrm{mM}$ ferrocene methanol solution with a $25 \mu \mathrm{m}$ Pt electrode. The pre-treatment of the copper samples was conducted in $0.1 \mathrm{M} \mathrm{KCl}+1$ $\mathrm{mM}$ BTAH solution. Tip-substrate distance: $15 \mu \mathrm{m}$. Tip potential: $+0.50 \mathrm{~V}$ vs. $(\mathrm{Ag} / \mathrm{AgCl}, 3 \mathrm{M} \mathrm{KCl})$. The $Z$ scale is the tip current in $\mathrm{nA}$. The sample was left at its spontaneous open circuit potential in the electrolyte.

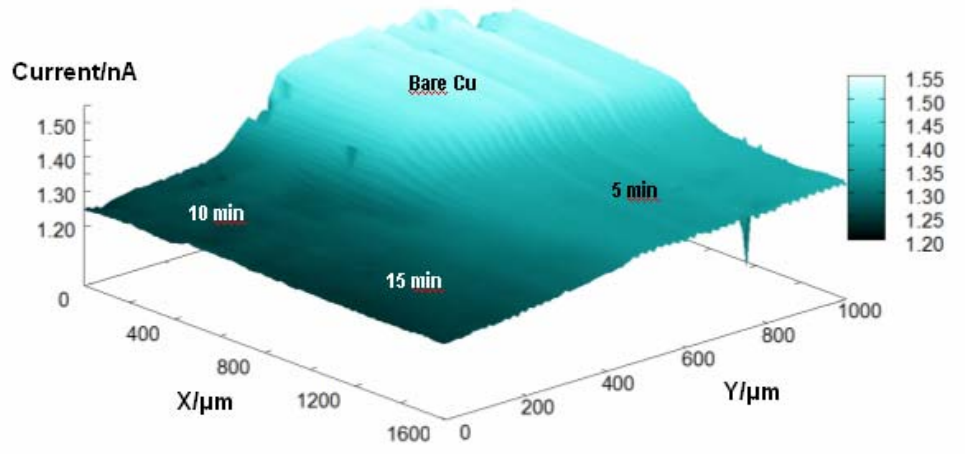

Figure 12: Image generated by SECM of a untreated $\mathrm{Cu}-\mathrm{Cu}-\mathrm{BTAH}$ (5 min pretreatment) - Cu-BTAH (10 min pre-treatment) - $\mathrm{Cu}$-BTAH (15 min pre-treatment) system immersed in $0.1 \mathrm{M} \mathrm{Na}_{2} \mathrm{SO}_{4}+1 \mathrm{mM}$ ferrocene methanol solution with a $25 \mu \mathrm{m}$ Pt electrode. The pre-treatment of the copper samples was conducted in $0.1 \mathrm{M} \mathrm{Na}_{2} \mathrm{SO}_{4}$ $+1 \mathrm{mM}$ BTAH solution. Tip-substrate distance: $15 \mu \mathrm{m}$. Tip potential: $+0.50 \mathrm{~V}$ vs. $(\mathrm{Ag} / \mathrm{AgCl}, 3 \mathrm{M} \mathrm{KCl})$. The $Z$ scale is the tip current in $\mathrm{nA}$. The sample was left at its spontaneous open circuit potential in the electrolyte. 


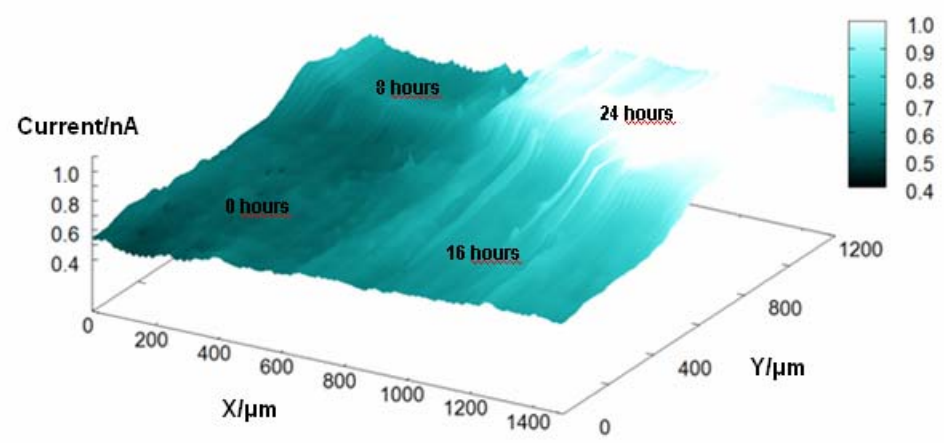

Figure 13: Image generated by SECM of a copper sample displaying 4 zones of different electrochemical activity during immersion in $0.1 \mathrm{M} \mathrm{Na}_{2} \mathrm{SO}_{4}+1 \mathrm{mM}$ ferrocene methanol solution with a $25 \mu \mathrm{m}$ Pt electrode. The copper sample was first treated during 7 days in $0.1 \mathrm{M} \mathrm{Na}_{2} \mathrm{SO}_{4}+1 \mathrm{mM}$ BTAH solution to form a $\mathrm{Cu}-\mathrm{BTAH}$ inhibitive film. The corrosion resistance characteristics of the $\mathrm{Cu}$-BTAH inhibitive film was investigated by exposing the sample to $1 \mathrm{M} \mathrm{NaCl}$ solution for the various times indicated on the figure. Tip-substrate distance: $15 \mu \mathrm{m}$. Tip potential: $+0.50 \mathrm{~V}$ vs. $(\mathrm{Ag} / \mathrm{AgCl}, 3 \mathrm{M} \mathrm{KCl})$. The $\mathrm{Z}$ scale is the tip current in $\mathrm{nA}$. The sample was left at its spontaneous open circuit potential in the electrolyte.

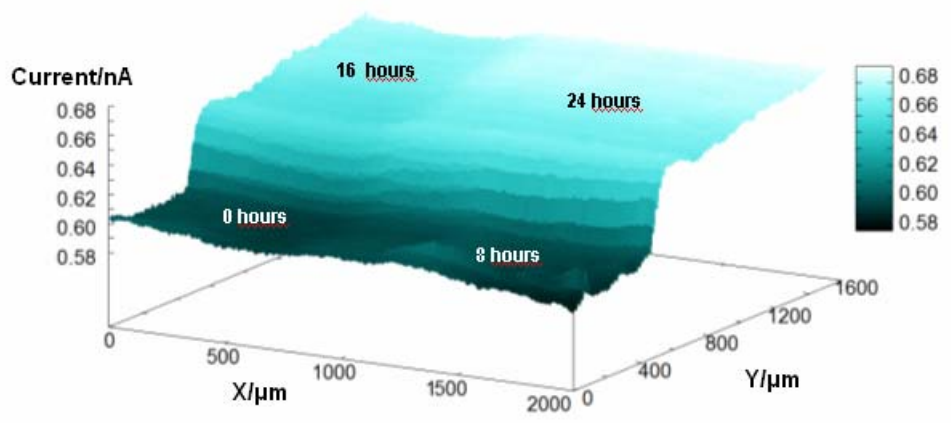

Figure 14: Image generated by SECM of a copper sample displaying 4 zones of different electrochemical activity during immersion in $0.1 \mathrm{M} \mathrm{KCl}+1 \mathrm{mM}$ ferrocene methanol solution with a $25 \mu \mathrm{m}$ Pt electrode. The copper sample was first treated during 7 days in $0.1 \mathrm{M} \mathrm{Na}_{2} \mathrm{SO}_{4}+1 \mathrm{mM}$ BTAH solution to form a $\mathrm{Cu}-\mathrm{BTAH}$ inhibitive film. The corrosion resistance characteristics of the $\mathrm{Cu}-\mathrm{BTAH}$ inhibitive film was investigated by exposing the sample to $1 \mathrm{M} \mathrm{NaCl}$ solution for the various times indicated on the figure. Tip-substrate distance: $15 \mu \mathrm{m}$. Tip potential: $+0.50 \mathrm{~V}$ vs. $(\mathrm{Ag} / \mathrm{AgCl}, 3 \mathrm{M} \mathrm{KCl})$. The $Z$ scale is the tip current in $\mathrm{nA}$. The sample was left at its spontaneous open circuit potential in the electrolyte. 

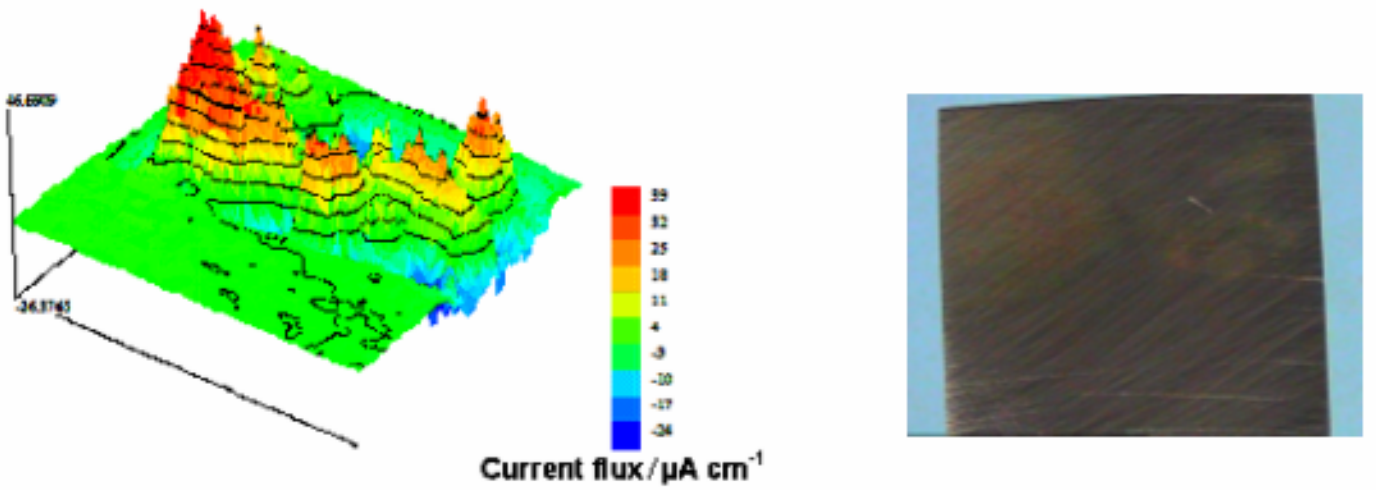

(A)
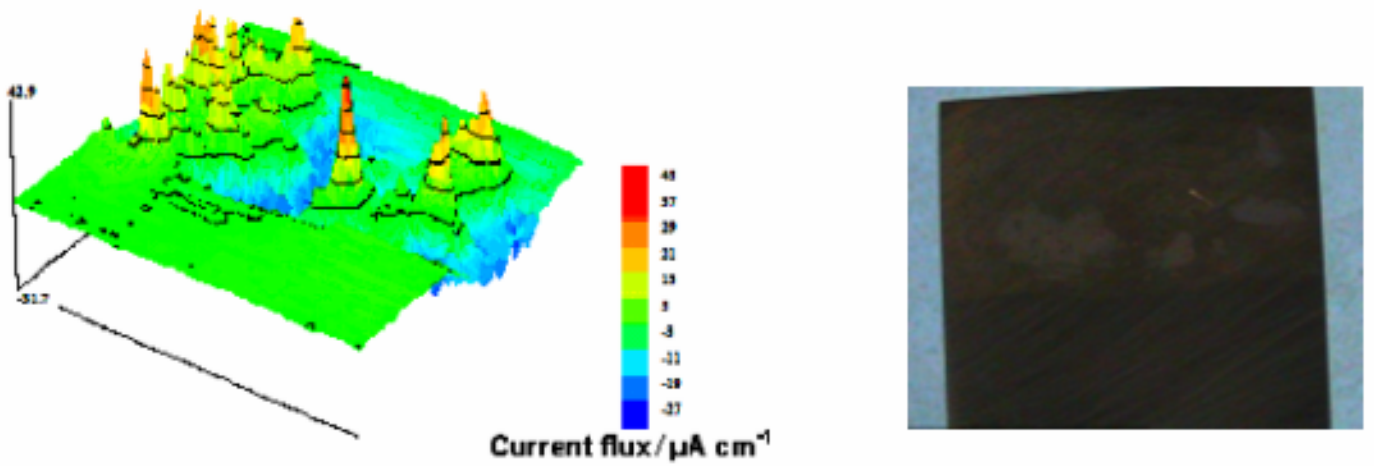

(B)

Figure 15: Images generated by SVET (left) and video microscope (right) of a $\mathrm{Cu}-$ BTAH (3 s pre-treatment) - Cu-BTAH (1 h pre-treatment) system immersed in $10 \mathrm{mM}$ $\mathrm{KCl}$ for (A) $15 \mathrm{~min}$, and (B) $195 \mathrm{~min}$. The pre-treatment of the copper samples was conducted in $0.1 \mathrm{M} \mathrm{Na}_{2} \mathrm{SO}_{4}+1 \mathrm{mM}$ BTAH solution for the chosen immersion times. Tip-substrate distance: $100 \mu \mathrm{m}$. The $Z$ scale is the ionic current in $\mu \mathrm{A} \mathrm{cm}^{-1}$. The figures represent an area of $8000 \mu \mathrm{m} \times 8000 \mu \mathrm{m}$ in $X$ and $Y$ directions. The sample was left at its spontaneous open circuit potential in the electrolyte. 